\title{
PROPOSTA DE EMENDA À CONSTITUIÇÃO N. 65 DE 2012: RÉQUIEM AO LICENCIAMENTO AMBIENTAL?
}

Heron José Santana Gordilho ${ }^{1}$

Universidade Federal da Bahia (UFBA)

Raissa Pimentel S. Siqueira ${ }^{2}$

Universidade Federal da Bahia (UFBA)

\section{RESUMO}

O presente artigo é uma nota legislativa, que a partir do método histórico-evolutivo, promove a análise da Proposta de Emenda Constitucional n. 65, de 12 de dezembro de 2012, que visa promover alterações ao procedimento de licenciamento de empreendimentos potencialmente causadores de significativo impacto, no sentido de torná-lo mais célere. A seção inaugural será dedicada à análise do licenciamento ambiental, enquanto instrumento da Política Nacional do Meio Ambiente, perquirindo a logicidade que permeia o procedimento trifásico, sem prejuízo da análise do rito especial conferido aos empreendimentos potencialmente causadores de significativo impacto ambiental. Em seguida, será relatada a tramitação da Proposta nas Casas Legislativas para, por fim, registrar fundamentadamente os efeitos que adviriam da eventual aprovação, a ruptura à lógica trifásica do licenciamento ambiental, além da violação aos princípios do poluidor-pagador e participação popular.

Palavras-chave: Estudo de Impacto Ambiental (EIA); licença ambiental; princípio da participação; princípio do poluidor-pagador; Relatório de Impacto Ambiental (RIMA).

1 Pós-doutor pela Pace University Law School. Doutor em Direito pela Universidade Federal de Pernambuco (UFPE). Professor do Programa de Pós-graduação em Direito na UFBA e na Universidade Católica de Salvador (UCSAL). Membro da World Academy of Art \& Science (WAAS). ORCID: https://orcid.org/0000-0001-8485-3729 / e-mail: heron@ufba.br.

2 Doutoranda em Direito Público e Mestre em Relações Sociais e Novos Direitos, área de concentração Direito Ambiental, pelo Programa de Pós-Graduação em Direito da UFBA. Especialista em Direito Imobiliário pela Universidade Salvador (UNIFACS). Professora assistente na Universidade Ruy Barbosa, professora convidada na UNIFACS e professora substituta na UFBA. ORCID: https://orcid. org/0000-0001-8364-0270 / e-mail: raissapimentelss@gmail.com. 


\section{CONSTITUTIONAL AMENDMENT PROPOSAL N. 65 FROM 2012: IT IS A REQUIEM FOR THE ENVIRONMENTAL LICENSING?}

\section{ABSTRACT}

This article is a legislative note that, based on the historical-evolutionary method, promotes the analysis of the Proposed Constitutional Amendment no. 65, of December 12, 2012, aimed at promoting changes to the licensing procedure of projects that potentially cause significant impact, in order to make it faster. The inaugural section will be devoted to the analysis of environmental licensing, as an instrument of the National Environmental Policy, seeking the logicality that permeates the three-phase procedure, without prejudice to the analysis of the special rite conferred to enterprises potentially causing significant environmental impact. Then, the proposal will be reported in the Legislative Houses to finally record the effects that would result from the eventual approval, the breach of the three-phase logic of environmental licensing, as well as the violation of the principles of polluter pays and popular participation.

Keywords: Environmental Impact Report (RIMA); Environmental Impact Study (EIA); environmental license; polluter pays principle; principle of participation. 


\section{INTRODUÇÃO}

Licenciamento ambiental é, sem dúvida, tema que suscita calorosas discussões entre os inúmeros agentes sociais, direta ou indiretamente, envolvidos nas querelas associadas ao binômio estabelecido entre crescimento econômico e salvaguarda dos recursos ambientais.

Por um lado, reverberam argumentos no sentido de que o procedimento administrativo, trifásico, por ser deveras complexo, moroso e dispendioso, acarreta prejuízos ao exercício das atividades econômicas responsáveis pela expansão do país. Por outro, ecoam acusações acerca da expedição de licenças e outros atos autorizativos de modo imponderado, lastreada em análises meramente formais de estudos viciados - porquanto realizados pelo próprio interessado -, à revelia da efetiva tutela do bem ambiental.

No contexto dos debates acerca da necessidade de aprimoramento da legislação ambiental, tramitou no Senado Federal a Proposta de Emenda Constitucional n. 65 de 2012, de 12 de dezembro de 2012, de lavra do Senador Acir Marcos Gurgacz e outros 3 , tendo por objetivo alterar o procedimento de licenciamento ambiental para empreendimentos potencialmente causadores de significativo impacto ambiental, no sentido de torná-lo mais ágil.

Pretendiam os congressistas signatários da aludida proposta promover emenda à Constituição Federal no sentido de incorporar um sétimo parágrafo a seu artigo 225, com a seguinte redação: “A apresentação do estudo prévio de impacto ambiental importa autorização para a execução da obra, que não poderá ser suspensa ou cancelada pelas mesmas razões a não ser em face de fato superveniente" (GURGACZ et al., 2012).

Como a justificativa do texto inicial defende a necessidade de imprimir celeridade à execução de obras públicas, conjectura-se que a alteração, se aprovada, implicaria, em realidade, tornar inócuo o processo de licenciamento ambiental de empreendimentos e/ou atividades, públicos ou privados.

A despeito dos argumentos sedimentados na justificativa publicada pelos proponentes, da leitura do enunciado normativo proposto, pode-se inferir a ocorrência de discrepâncias entre alegações fundantes e a moldura

3 Demais senadores signatários da proposta: Antônio Carlos Valadares, Armando Monteiro, Casildo Maldaner, Cássio Cunha Lima, Cidinho Santos, Clésio Andrade, Cristovam Buarque, Cyro Miranda, Eduardo Amorim, Eduardo Lopes, Eunicio Oliveira, Gim Argello, Humberto Costa, Inácio Arruda, Jayme Campos, João Vicente Claudino, Lobão Filho, Marco Antônio Costa, Mário Couto, Paulo Bauer, Romero Jucá, Sérgio "Petecão", Sérgio Souza, Vital do Rêgo, Waldemir Moka, Walter Pinheiro, Wellington Dias e Wilder Morais. 
jurídica existente acerca do licenciamento ambiental, em especial no que atine à necessidade de observância do procedimento trifásico e à fidelidade aos princípios da prevenção, do poluidor-pagador e da participação popular.

O tópico inaugural deste artigo será dedicado ao licenciamento ambiental, enquanto instrumento da Política Nacional do Meio Ambiente. Para tanto, serão anotadas considerações preambulares acerca de externalidades ambientais, e um sucinto exame dos fundamentos dos princípios do poluidor-pagador e da prevenção.

Em seguida será feita uma análise do procedimento trifásico do licenciamento ambiental, buscando-se inferir sua logicidade e conferindo enfoque aos requisitos essenciais e efeitos jurídicos da expedição de cada uma das três licenças cumulativas e necessárias ao funcionamento do empreendimento ou atividade.

Mais à frente, será feito um estudo das peculiaridades inerentes ao licenciamento ambiental em empreendimentos potencialmente causadores de significativo impacto ambiental, àqueles aos quais a Constituição Federal de 1988 cuidou de exigir um rito especial de procedimento administrativo, com a realização de Estudo Prévio de Impacto Ambiental e subsequente viabilização de instâncias de manifestação popular acerca dos resultados.

Por fim, tendo em vista que esses empreendimentos foram o objeto imediato das mudanças constitucionais propostas, será feita uma análise da PEC n. 65/2012, e a título de esboço histórico, serão analisados a tramitação da Proposta nas Casas Legislativas e os efeitos que adviriam da aprovação da Proposta, momento em que buscar-se-á elucidar as incongruências percebidas entre os argumentos sedimentados pelos congressistas signatários motivados a justificar a alteração pretendida e o real significado/efeito jurídico insculpido no dispositivo que se pretende ver incorporado ao diploma constitucional.

\section{LICENCIAMENTO AMBIENTAL}

Para melhor compreensão do contexto jurídico que permeia a propositura da PEC n. 65/2012, um sobrevoo por premissas que conformam o licenciamento ambiental faz-se conveniente, razão pela qual serão a seguir arregimentadas algumas informações essenciais acerca do procedimento administrativo em questão. 


\subsection{Fundamentos principiológicos do licenciamento ambiental}

Na medida em que a Constituição da República Federativa do Brasil eleva o meio ambiente ecologicamente equilibrado à condição de valor a ser tutelado, a própria carta magna, em seu artigo 170, consagra a livre iniciativa entre os fundamentos da ordem econômica brasileira, garantindo o exercício da atividade produtiva no país.

Como consequência, muitas vezes inevitável, da atividade produtiva e de consumo, é possível verificar a ocorrência de perdas imputadas a pessoas estranhas à relação econômica existente entre produtor e prestador de serviços, e consumidor e beneficiário - os outsiders, portanto - tendo como característica a inexistência de compensação aos prejudicados (ARAGÃO, 2014).

Tais efeitos nocivos, ditos externos aos mercados, porque não são contabilizados nos custos e decisões daqueles que os produzem, representam preço zero, configurando externalidades negativas ${ }^{4}$.

Alexandra Aragão (2014) ilustra o conceito mencionando no ato de aquisição de um automóvel: a relação existente entre consumidor e fornecedor do bem certamente promoverá benefícios aos negociantes. Todavia, a circulação de um novo veículo pode implicar o incremento de congestionamentos no tráfego, gerando, assim, impactos aos demais condutores.

Note-se que, à luz desse exemplo, a autora aponta a ocorrência de uma externalidade social, pois diante do mesmo cenário é possível também vislumbrar uma externalidade ambiental, na medida em que o congestionamento no tráfego corroborará com o incremento da poluição atmosférica, em razão da emissão de gases associados ao efeito estufa. Outro exemplo elucidativo é aquele de uma indústria que, em decorrência de seu processo produtivo, gera altos níveis de poluição da água e do ar, tornando-as de qualidade inferior para fruição da população.

A questão das externalidades negativas torna-se alarmante quando reiteradamente ela afeta o meio ambiente, podendo ocasionar, com o decurso do tempo, seu esgotamento, como ilustrado no clássico A Tragédia dos Comuns, de Garrett Hardin (1968).

4 Em simples termos, entende-se por externalidade o impacto causado pelas ações de um determinado indivíduo ou grupo a terceiros próximos, todavia não participantes, seja direta ou indiretamente, da ação geradora do resultado. Podem afigurar-se positivas, quando o resultado acarretado ao terceiro lhe for benéfico, ou negativas, hipótese em que àquele terceiro passa a subsistir um prejuízo (usualmente, uma desvalorização de seus bens, sejam corpóreos ou incorpóreos) (HOWDEN, 2013). 
O problema descrito por Hardin envolve um grupo de pastores que utilizam uma área comum para pastagem de seus rebanhos, onde cada pastor é consciente acerca dos custos e benefícios relacionados ao acréscimo de um animal à área de pastagem comum.

O lucro que ele vai obter a partir do novo animal, implicará custos e implicações decorrentes da manutenção do animal na área, tais como a redução da quantidade e qualidade do pasto disponível, custos estes que serão compartilhados entre todos os pastores. Sucede que, se todos os pastores assim agirem, após um tempo a área comum certamente será destruída (1968).

A hipótese hardiniana é aplicável aos bens ambientais, na condição de bens de uso comum do povo livremente acessíveis à população. Os indivíduos que menos exploram os recursos naturais acabam por assumir custos gerados por aqueles que o utilizam em maior escala (MACHADO, 2015).

Alexandra Aragão explica que a propriedade comum e o livre acesso aos bens ambientais acabam por implicar o desenvolvimento de atividades econômicas sem o devido cálculo dos custos sociais, entre os quais se incluem as externalidades, uma vez que somente são analisados os custos de produção (ARAGÃO, 2014).

A inadequada internalização das externalidades negativas corrobora não somente com a exposição dos recursos naturais ao risco de uma severa degradação, mas também à configuração de injustiças sociais.

Para a correção desse cenário, uma resposta estatal é imperiosa: deve o Estado, preventivamente, manejar os instrumentos de política pública de que dispõe no sentido de evitar a ocorrência das externalidades socioambientais.

Nessa toada, para orientar a conduta do poder público a induzir a internalização das externalidades negativas decorrentes da atividade causadora de degradação ambiental, surge o princípio do poluidor-pagador, a partir da publicação da Recomendação C (72) 128, editada em 1972 pela Organização para a Cooperação e para o Desenvolvimento Econômico (OCDE), visando proteger o meio ambiente a partir da harmonização dos custos da produção e evitar distorções nos preços dos produtos no âmbito do mercado internacional (PIMENTA; GORDILHO, 2018, p. 365) 5 .

5 “[...] Os recursos ambientais são, em geral, limitados e sua utilização em atividades de produção e de consumo pode levar à deterioração. Quando o custo desta deterioração não é devidamente computado no sistema de preços, o mercado não reflete a escassez de tais recursos, tanto a nível nacional e internacional. O princípio a ser utilizado para alocar os custos de prevenção da poluição e medidas de controle para incentivar o uso racional dos recursos ambientais escassos e evitar distorções no 
Positivado como um princípio jurídico, embora de matriz econômica, aplicável à política ambiental europeia, delineando a temática dos custos de prevenção e restauração pertinentes às atividades poluidoras, o mandamento foi incorporado à Declaração do Rio sobre Meio Ambiente e Desenvolvimento (Princípio 16), como produto da Conferência das Nações Unidas sobre Meio Ambiente e Desenvolvimento, realizada no Brasil em 1992.

A lógica que permeia o princípio do poluidor-pagador é uma lógica econômica, pois não está falando em um mandamento preeminentemente repressivo e sancionatório, uma vez que inúmeras atividades e empreendimentos resultam em impactos negativos ao meio ambiente e, ainda assim, como corolário do desenvolvimento sustentável, são regularmente licenciados pelo poder público, mas em uma diretriz consternatória, de índole preventiva.

Por meio da incorporação desse princípio ao universo jurídico, evita-se que ocorra a privatização dos lucros e socialização dos prejuízos, impondo ao poluidor a assunção dos custos necessários à mitigação e/ou eliminação dos prejuízos sociais decorrentes da atividade produtiva (LEITE, 2015).

Um princípio, entrementes, uma vez abarcado pelo ordenamento jurídico como mandamento de otimização de condutas, depende de instrumentos específicos voltados a sua efetiva operacionalização, de modo que o princípio do poluidor-pagador procura limitar a discricionariedade do poder público, uma vez que impede que a Administração permita que àqueles que não participaram da ação que resultou na poluição sofram os prejuízos decorrentes da ação lesiva.

Os princípios da precaução e da prevenção são os dois subprincípios concretizadores do princípio do poluidor-pagador: a precaução, quando a atividade é suscetível de originar contaminação ambiental e exige a adoção de cuidados excepcionais em sua execução; e a prevenção em sentido estrito, quando existe a certeza de um dano a ser provocado por determinado tipo de atividade, o que exige a adoção de medidas mitigadoras (PIMENTA; GORDILHO, 2018).

O licenciamento ambiental e a correlata possibilidade de imposição de condicionantes irrompem como instrumentos de operacionalização

comércio internacional e investimento é o chamado 'princípio poluidor-pagador'. Esse princípio significa que o poluidor deve arcar com as despesas de realização acima mencionadas, medidas decididas pelas autoridades públicas para assegurar que o ambiente está em estado aceitável. Em outras palavras, o custo dessas medidas deve ser refletido no custo dos produtos e serviços que causam a poluição na produção e/ou consumo" (tradução nossa). 
do princípio da prevenção, na medida em que prescreve, seja ao poder público ou aos legislados, a adoção de intervenções no sentido de evitar a ocorrência de danos ambientais minimamente previsíveis.

Na medida em que o órgão ambiental impõe ao empreendedor, como condição sine qua non à expedição de licença ambiental, por exemplo, a obrigatoriedade de instalar determinado filtro nas chaminés de sua planta industrial, ele realiza uma intervenção profilática, com o intuito de evitar a concretização da emissão de gases poluentes em níveis nocivos.

Evidencia-se o caráter preventivo na medida em que impõe ao poluidor a adoção de providências voltadas à mitigação e contenção de danos - e custos - que seriam absorvidos pela sociedade sob forma de externalidades, caso as medidas reparatórias não fossem exigidas.

Busca-se, também, desencorajar a conduta socialmente desinteressante do empreendedor, a partir da imputação da necessidade de absorção dos custos com ações voltadas à prevenção de danos ambientais, o que implica a elevação do valor final do produto ou serviço (ROCHA, 2013).

Em paralelo, à medida que os custos são repassados ao consumidor final, a justiça social é prestigiada, uma vez que aqueles que efetivamente se beneficiam do produto ou serviço são onerados, não sofrendo a coletividade com os custos da poluição, sejam financeiros ou sociais.

Somente no curso do procedimento de licenciamento ambiental, momento em que o diagnóstico dos possíveis danos e externalidades são realizados, a partir da análise dos estudos de impacto ambiental, é possível à manifestação do poder público estabelecer as condicionantes da autorização da atividade ou empreendimento.

\subsection{Procedimento trifásico de licenciamento ambiental}

O licenciamento ambiental surge no ordenamento jurídico brasileiro com a Lei n. 6.938/81, que instituiu a Política Nacional de Meio Ambiente (PNMA), que o elegeu como um de seus mais preeminentes instrumentos (BRASIL, 1981, art. $9^{\circ}$ ).

Trata-se de um procedimento administrativo por meio do qual o órgão ambiental competente autoriza a construção, instalação, ampliação e funcionamento de atividades e/ou empreendimentos utilizadores de recursos ambientais, efetiva ou potencialmente poluidores, ou capazes de causar degradação ambiental.

A dinâmica do licenciamento ambiental enquanto procedimento 
necessariamente trifásico foi arregimentada pelo Decreto n. 99.274, de 6 de junho de 1990, que ao regulamentar a PNMA, cuidou de consignar a obrigatoriedade de obtenção, pelo pretenso empreendedor, de três licenças distintas, cumulativas e concedidas sucessivamente, a saber: Licença Prévia (LP), Licença de Instalação (LI) e Licença de Operação (LO) (BRASIL, 1990, art. 19).

A obtenção da primeira delas, a LP, não importa em autorização para realização da atividade ou para que o empreendedor inicie a execução das obras necessárias à efetiva implantação de seu estabelecimento. Ela apenas, e tão somente, simboliza a aprovação, pelo poder público, da localização e concepção do projeto, que deve ser implementado pelo interessado somente após a análise e discussão dos estudos ambientais empreendidos pelo corpo técnico do órgão licenciador visando atestar sua viabilidade ambiental (CONAMA, 1986, art. $8^{\circ}$ ).

Por ocasião da expedição da LP serão arroladas as condicionantes, que são medidas de controle e ações necessárias à absoluta correção ou, ao menos, mitigação dos impactos ambientais negativos a serem gerados pelo empreendimento, e cuja incorporação no projeto executivo revela-se indispensável à consecução da licença subsequente (BECHARA, 2007).

Assim, depois de manifestado o interesse em realizar determinado empreendimento e obtida a LP, ao empreendedor incumbe realizar as adequações no projeto, de modo a incorporar as diretrizes e condicionantes estipuladas, e então, mais uma vez, dirigir-se ao órgão licenciador munido de Projeto Executivo minuciosamente elaborado, dele constando, entre outros aspectos, o detalhamento dos processos a serem adotados durante a implantação de tecnologias a serem empregadas para fins de mitigação dos impactos ambientais negativos, à guisa de solicitar a autorização para a iniciar a implantação, havida com a expedição da LI.

Depois de construída a infraestrutura do empreendimento, nos termos da LI, o empreendedor ainda não resta autorizado a iniciar suas atividades, fazendo-se mister uma checagem final por parte do órgão ambiental para verificação do efetivo cumprimento das condicionantes e parâmetros consignados, avaliação que finalmente permitirá a obtenção da LO (CONAMA, 1986, art. $8^{\circ}$ ).

A multiplicidade de fases do procedimento de licenciamento ambiental justifica-se pela necessidade de serem tecidos ao projeto os ajustes necessários à compatibilização entre a realização da atividade econômica e a salvaguarda do meio ambiente.

Segundo Maria Luiza Granzinera (2014, p. 421): 
[...] o licenciamento ambiental não se destina a inviabilizar a implantação de um empreendimento. A sua função precípua é buscar todos os meios possíveis para essa implantação, a menos que os riscos de dano evidenciem falta de segurança quanto aos efeitos desse empreendimento no futuro.

Assim, após percepção dos anseios do empreendedor, e diante das características da atividade a ser desenvolvida, bem como do diagnóstico do meio (sob enfoque ecológico e social), o órgão técnico disporá de duas oportunidades para determinar as adequações necessárias ao projeto, de modo a aproveitá-lo, corrigidos os aspectos frágeis pelo interessado.

\subsection{Licenciamento de empreendimentos potencialmente causadores de significativo impacto - procedimento extraordinário: EIA/RIMA como exigência constitucional}

Não obstante a necessária observância ao procedimento trifásico de licenciamento ambiental, o legislador constituinte cuidou de consignar a obrigatoriedade de elaboração de Estudo Prévio de Impacto Ambiental (EIA) para empreendimentos potencialmente causadores de vultoso impacto ambiental, impondo ao poder público a obrigação de "exigir, na forma da lei, para instalação de obra ou atividade potencialmente causadora de significativa degradação do meio ambiente, estudo prévio de impacto ambiental, a que se dará publicidade" (BRASIL, 1988, art. 225, § 1, IV).

O EIA representa a mais robusta ferramenta associada ao licenciamento ambiental, visto que arregimenta dados dos mais diversos espectros e eixos, para uma criteriosa análise dos impactos ambientais ao cenário paradigmático decorrentes de determinada atividade.

A partir da edição do primeiro ato normativo de lavra do Conselho Nacional do Meio Ambiente (CONAMA), a Resolução n. 001, de 23 de janeiro de 1986, definiu o EIA como um estudo técnico a ser realizado por equipe multidisciplinar devidamente habilitada, com o objetivo de, entre outras diretrizes, identificar e avaliar sistematicamente os impactos ambientais gerados nas fases de implantação e operação do projeto proposto pelo pretenso empreendedor, contemplando, inclusive, a elaboração de alternativas tecnológicas e de localização (CONAMA, 1986, arts. $5^{\circ}$ e $7^{\circ}$ ).

Trata-se, em simples termos, de complexo estudo a ser realizado por equipe composta por profissionais das mais diversas áreas, tais como biólogos, engenheiros agrônomos, e mesmo antropólogos, entre outros, para subsidiar a análise e decisão do órgão licenciador acerca da autorização 
da instalação e posterior operação da atividade e/ou empreendimento.

A Constituição Federal estabeleceu a necessidade de ampla divulgação do conteúdo EIA junto à sociedade, para colheita de questionamentos e sugestões, e por se tratar de um documento preeminentemente técnico, o EIA deve obrigatoriamente vir acompanhado de um documento sintético e linguagem acessível, que consigne as conclusões do estudo, que é o Relatório de Impactos ao Meio Ambiente (RIMA). ${ }^{6}$

No que atine ao procedimento, uma vez manifestado o interesse do empreendedor em realizar determinada atividade considerada potencialmente causadora de significativa degradação ambiental, e tendo sido elaborado o EIA/RIMA nos parâmetros estipulados pelo órgão ambiental, é chegado o momento de ser viabilizada a participação da sociedade.

Para tanto, deverá o órgão licenciador, após o recebimento do aludido estudo, noticiar a sociedade acerca de sua existência, bem como da possibilidade de agendamento de audiências públicas para explicitar de seu conteúdo material e receber sugestões, momento denominado por Paulo Afonso Leme Machado (2015, p. 299) como "fase de comentários", a partir da publicação de editais específicos em veículo de comunicação local, consignando um interregno mínimo de 45 dias para manifestação de interessados (CONAMA, 1987, art. $1^{\circ}$ ).

As audiências públicas poderão ser agendadas de ofício pelo próprio órgão licenciador de ofício, mas também Ministério Público ou qualquer entidade civil legalmente instituída, ou mesmo por um grupo composto por 50 ou mais cidadãos. Tamanha é a importância conferida às audiências públicas que sua não realização, havendo prévia solicitação por parte de algum dos legitimados, implicará nulidade da licença (CONAMA, 1987, art. $2^{\circ}$ ).

Não suficiente, cópias do EIA/RIMA devem constar do fólio de documentos do órgão licenciador, devendo ser franqueado o acesso de qualquer interessado a estas, antes mesmo da realização das oitivas populares, sob risco de invalidação da fase de comentários e, por conseguinte, da licença ambiental posteriormente expedida, por configurar afronta ao quanto disposto no art. 25, $\S 1^{\circ}$, IV, da CF. (MACHADO, 2015).

6 Assim explica Paulo Afonso Leme Machado: "O estudo é de maior abrangência que o relatório e o engloba em si mesmo. O EPIA compreende o levantamento da literatura científica e legal pertinente, trabalhos de campo, análises de laboratório e a própria elaboração do relatório" (MACHADO, 2015, p. 277). 


\subsubsection{EIA e o princípio da participação popular}

A participação dos interessados na fase de comentários representa a operacionalização do princípio da participação social, que é o Princípio 10 da Declaração do Rio de Janeiro sobre Meio Ambiente e Desenvolvimento, que destaca a necessidade do compartilhamento das decisões entre poder público e sociedade (ONU, 1992).

Para a plena implementação do princípio da participação popular, o Estado deve promover o acesso à informação e aos mecanismos de controle e mitigação dos impactos decorrentes das decisões adotadas em sede de políticas públicas.

A participação pública, o acesso à informação e o acesso à justiça ${ }^{7}$ devem ser examinados de modo amalgamado, como dimensões estratificadas de um dever do Estado, voltado a garantir a efetivação do direito fundamental ao meio ambiente ecologicamente equilibrado, nos moldes do disposto no caput do artigo 225 da Constituição Federal.

A existência de um direito fundamental ao meio ambiente equilibrado impõe um dever correlato ao Estado de assegurar a eficácia desse direito a partir da implementação de aparatos procedimentais, conglobando ações positivas e negativas.

Ao se considerar o direito à participação na tomada de decisões em matéria de meio ambiente como uma garantia fundamental, qualquer omissão do Estado em promover o acesso à informação - in casu, a partir da não disponibilização do EIA/RIMA para análise e registro de comentários - ou não viabilizar, de modo substancial, a participação da população nos procedimentos administrativos que culminarão na tomada de decisão, como a não realização de audiências públicas ou a realização destas em local de difícil acesso aos interessados, pode ser considerado embaraço ao exercício de um direito ou mesmo eliminação de uma posição jurídica.

É que o princípio da participação é consectário lógico do princípio democrático, princípio estruturante de Estado Democrático de Direito, que além de congregar normas procedimentais, impõe ao poder público a adoção de medidas que garantam o exercício da participação pelos cidadãos na tomada de decisão ambiental (SARLET; FENSTERSEIFER, 2014).

7 Participação pública, acesso à informação e acesso à justiça, aliás, conformam o Tripé de Aarhus, resultado da Convenção sobre Acesso à Informação, Participação do Público no Processo de Tomada de Decisão e Acesso à Justiça em Matéria de Meio Ambiente, ocorrida em Aarhus, na Dinamarca, em 25 de junho de 1998, que embora o Brasil não conste entre os signatários - por tratar-se de um evento realizado no âmbito da União Europeia - figura como documento balizador das ações estatais em âmbito internacional (CONSELHO DA UNIẪO EUROPEIA, 2015). 
Frank Fischer (2000) registra a importância do estabelecimento de instâncias de participação direta dos cidadãos em escolhas públicas que envolvam o meio ambiente, sugerindo que o modelo de democracia representativa - em que aos mandatários é dada a prerrogativa de converter a opinião pública em efetiva tomada de decisão - acaba por implicar uma concepção elitista de democracia, na medida em que mesmo os representantes mais liberais, ${ }^{8}$ via de regra, têm uma visão distorcida dos anseios da sociedade.

Assim, foi manifesto o animus do legislador constituinte ao submeter o licenciamento de empreendimentos e atividades potencialmente causadoras de significativa degradação ambiental à discussão e controle social, justamente em razão da magnitude dos impactos a serem acarretados.

Somente após a viabilização da manifestação popular é que o órgão licenciador poderá encerrar a fase preliminar de avaliação dos impactos provenientes da realização do empreendimento, ponderando vantagens e malefícios socioambientais.

\section{PROPOSTA DE EMENDA CONSTITUCIONAL N. 65/2012}

Assentadas as premissas precedentes, pode-se adentrar a análise das implicações que possivelmente advirão da eventual aprovação da Proposta de Emenda Constitucional n. 65 de 2012.

\subsection{Breve síntese da tramitação}

Conforme apontado nas notas introdutórias, a proposta em análise tem o intuito de promover alterações ao procedimento de licenciamento ambiental em empreendimentos potencialmente causadores de significativo impacto ambiental, visando torná-lo mais célere.

Protocolada no Senado Federal em 13 de dezembro de 2012, ela foi imediatamente remetida à Comissão de Constituição, Justiça e Cidadania (CCJ), e por distribuição datada de 02.04.2013, coube ao Senador Armando Monteiro, que em 04.02.2014, por motivos não divulgados, devolveu o projeto à Secretaria da CCJ, sem qualquer análise, para nova distribuição.

Em 01.10.2015, após um ano e sete meses sem tramitação, por designação do presidente da CCJ, Senador Waldir Maranhão, a matéria foi 8 A expressão parece ser empregada pelo autor no sentido de adeptos a participação popular. 
encaminhada ao então Senador Blairo Maggi para análise e elaboração do relatório preliminar. ${ }^{9}$

Em 07.03.2016, o Senador Blairo Maggi, após análise dos requisitos formais e materiais necessários ao prosseguimento do feito, encaminhou seu relatório à Comissão, consignando seu voto favorável à aprovação da Proposta: "[...] opino pela constitucionalidade, juridicidade e boa técnica legislativa da Proposta de Emenda à Constituição n. 65, de 2012, e voto, quanto ao mérito, por sua aprovação" (GURGACZ, 2012).

Ato contínuo à divulgação do voto do Relator, a matéria fora incluída em pauta para a apreciação pelos demais membros da Comissão, de modo que, no dia 27.04.2016, após deliberação do órgão, o aludido Relatório foi adotado como Parecer n. 469 de 2016 da CCJ (SENADO FEDERAL, 2016), chancelando a continuidade da tramitação da PEC 65/12, que foi remetida ao Plenário do Senado Federal para votação.

Em 18.05.2016, foi protocolado pelo Senador Randolfe Rodrigues o requerimento n. 358/2016, solicitando a devolução da PEC 65/12 para tramitação conjunta com a PEC 153/15, ainda em análise na CCJ, editada com o escopo de alterar o art. 225 da Constituição Federal para incluir, entre as incumbências do poder público, a promoção de práticas e a adoção de critérios de sustentabilidade em seus planos, programas, projetos e processos de trabalho, por se tratarem de propostas antagônicas de matérias associadas (RODRIGUES, 2016a).

$\mathrm{O}$ requerimento formulado pelo Senador pernambucano foi deferido em 19.05.2016, de modo que a Proposta foi devolvida à CCJ, para nova apreciação, e em 02.06.2016, por designação do Presidente da Comissão, Randolfe Rodrigues foi nomeado relator. ${ }^{10}$

O Senador Rodrigues, sete dias após o recebimento do documento, se manifestou pela inconstitucionalidade da PEC 65/12, recomendando seu arquivamento, e pela constitucionalidade da PEC 153/15 (RODRIGUES, 2016b).

Após apresentação desse novo Relatório, enquanto o feito restava sobrestado no aguardo de inclusão em pauta para votação pelos demais membros da Câmara, foram recebidas pela CCJ manifestações de lavra de órgãos diversos, alguns no sentido de questionar a constitucionalidade da PEC 65/12, outros expressando anuência à constitucionalidade, situação

9 Tramitação disponível em: https://www25.senado.leg.br/web/atividade/materias/-/materia/109736. Acesso em: 25 nov. 2019.

10 Em 12.05.2016, o Sen. Blairo Maggi foi nomeado Ministro da Agricultura, Pecuária e Abastecimento pelo então Presidente da República Interino, Michel Temer. 
que, por certo, veio a corroborar com a aprovação, pela Comissão, em 03.08.2016, do requerimento firmado pelos Senadores Randolfe Rodrigues e Acir Gurgacz (2016), no sentido de viabilizar a retirada das Propostas da pauta de votação para que pudessem ser realizadas, em caráter preparatório, audiências públicas específicas sobre esse impasse.

Em 21.12.2018, a proposição fora arquivada, nos termos do $\S 1^{\circ}$ do art. 332 do Regimento Interno, isto é, face ao encerramento de legislatura, embora não tenha havido apreciação de mérito, o que permite que ela seja desarquivada a qualquer tempo, à requerimento dos proponentes. ${ }^{11}$

\subsection{Implicações práticas da eventual aprovação}

Da análise do documento inicial da PEC 65/2012, pode-se inferir que a proposta apresentada tem o escopo de acrescentar um sétimo parágrafo ao artigo 225 da Constituição Federal, com a seguinte redação: “A apresentação do estudo prévio de impacto ambiental importa autorização para a execução da obra, que não poderá ser suspensa ou cancelada pelas mesmas razões a não ser em face de fato superveniente" (GURGACZ et al., 2012).

Entre as razões arregimentadas pelos proponentes com o objetivo de justificar a emenda, prepondera a necessidade de imprimir celeridade à execução de obras capitaneadas pelo poder público, uma vez que obras inacabadas ou suspensas em decorrência de omissões no licenciamento ambiental acabam por onerar a máquina estatal, prejudicando o interesse social, além de imputar uma reputação negativa ao governante.

Segundo Gurgacz:

Uma das maiores dificuldades da Administração Pública brasileira, e, também uma das razões principais para o seu desprestígio, que se revela à sociedade como manifestação pública de ineficiência, consiste nas obras inacabadas ou nas obras ou ações que se iniciam e são a seguir interrompidas mediante decisão judicial de natureza cautelar ou liminar, resultantes, muitas vezes, de ações judiciais protelatórias. [...] Nesses procedimentos, perde-se muito tempo e desperdiçam-se recursos públicos vultosos, em flagrante desrespeito à vontade da população, à soberania popular, que consagrara, em urnas, um programa de governo, e com ele, suas obras e ações essenciais. Tudo isso ocorre em flagrante prejuízo não ao prefeito ou à prefeitura, apenas, mas para todos os habitantes do lugar. Ademais disso, é sabidamente custoso manter uma obra pública paralisada, e esses custos são muito mais do que financeiros, pois até mesmo a democracia e a representação são desgastadas quando estamos diante de quadros dessa natureza. [...] Por isso, a proposta que ora apresentamos

11 Até o momento do encerramento do presente escrito, não foram agendadas as audiências públicas.

Veredas do Direito, Belo Horizonte, ·v.16 · n.36 · p.279-299 · Setembro/Dezembro de 2019 
assegura que uma obra uma vez iniciada, após a concessão da licença ambiental e demais exigências legais, não poderá ser suspensa ou cancelada senão em face de fatos novos, supervenientes à situação que existia quando elaborados e publicados os estudos a que se refere a Carta Magna (GURGACZ et al., 2012).

Em uma simples leitura das justificativas apresentadas pela PEC $65 / 12$, percebe-se a incongruência entre dispositivo e motivos fundantes da proposta, uma vez que o dispositivo não diferencia obra pública ou privada, alegando que a morosidade e as intervenções na tramitação do licenciamento violam o interesse público.

O dispositivo propõe que o licenciamento ambiental para a implantação de qualquer empreendimento ou atividade pública ou privada decorra do simples depósito do EIA no órgão ambiental, além de estabelecer uma garantia constitucional de que as obras de implantação dessas atividades ou empreendimentos não possam ser interrompidas por eventuais divergências no tocante ao conteúdo material do EIA apresentado.

Acontece que a elaboração e a análise do EIA pelo órgão ambiental são etapas que necessariamente precedem a expedição das licenças ambientais, e a primeira delas, a LP, deverá não somente considerar os resultados de avaliações anteriormente realizadas, quando da chancela da viabilidade do projeto, mas também considerar as possíveis condicionantes e medidas mitigadoras apontadas pelo EIA.

A autorização para o início das obras de implantação do empreendimento somente pode ser concedida após a constatação de que as medidas mitigadoras e condicionantes, fixadas com o objetivo de reduzir impactos e evitar externalidades socioambientais, foram minimamente cumpridas, de modo que a adoção pelo interessado das medidas consignadas na LP se constituem em condição sine qua non para a obtenção da LI.

A afirmação "Por isso, a proposta que ora apresentamos assegura que uma obra uma vez iniciada, após a concessão da licença ambiental e demais exigências legais, não poderá ser suspensa ou cancelada senão em face de fatos novos, [...]" (GURGACZ et al., 2012) é inconsistente, já que não se pode falar em concessão da licença ambiental antes do início da obra. Pelo contrário. O texto assegura, na contramão da lógica e mesmo da argumentação lançada, a possibilidade de construir sem que as LP e LI sejam concedidas previamente.

É preciso destacar os argumentos no sentido de que apenas estarse-ia adiando a análise das projeções dos dados constantes do EIA - tais como a estipulação de condicionantes e as medidas mitigadoras - para 
um momento posterior ao início da obra, de modo que a autorização seria precária, permitindo uma posterior adequação do projeto.

Não nos parece que seja esta a intenção da PEC 65/12, uma vez que ela estabelece que a apresentação do EIA "[...] importa autorização para a execução da obra, que não poderá ser suspensa ou cancelada pelas mesmas razões a não ser em face de fato superveniente" (GURGACZ et al., 2012).

Segundo Daniel Degenszajn (2010, p. 85):

\begin{abstract}
Fato superveniente (lat. superveniens) em singela definição é o fato que ocorre depois ou que sobrevém (sobreveniente). Para o processo, a modesta definição encontra correspondência no fato havido ulteriormente à distribuição da petição inicial, ou seja, o fato que vem a seguir à propositura da demanda.
\end{abstract}

Se compararmos a definição de superveniência no processo civil com o procedimento administrativo do licenciamento ambiental, vamos perceber que o enunciado aduz que a obra não poderá ser suspensa "pelas mesmas razões", isto é, por aquelas razões já consignadas do estudo apresentado, ainda que não analisadas.

Eis a estrutura silogística do enunciado:

- Premissa 1: a apresentação do EIA importa autorização para a execução da obra;

- Premissa 2: iniciada a execução da obra, esta não poderá ser suspensa ou cancelada com esteio nos dados consignados no EIA;

- Premissa 3: iniciada a execução da obra, esta somente poderá ser suspensa ou cancelada com em razão de fato superveniente a apresentação do EIA.

Poder-se inferir, portanto, como resultado de interpretação lógico-dedutiva, que a posterior análise dos dados já arrolados no EIA antes da expedição da autorização não poderá configurar fato superveniente, porquanto não é passível de consideração como um fato novo.

A PEC 65/12 afirma que a morosidade no procedimento de licenciamento ambiental fere a democracia, uma vez que os governantes eleitos pelo povo têm uma procuração prévia para decidir sobre a conveniência e oportunidade da realização de obras públicas no interesse da sociedade. A decisão tomada em benefício da coletividade espelharia, portanto, o exercício da representação indireta.

Acontece que a democracia deliberativa é exercida por meio de instâncias diretas, intermediárias e indiretas, e em matéria de meio ambiente, o exercício da maneira mais direta possível é a manifestação do próprio 
corpo social por meio das instâncias propositivas, como as audiências públicas do EIA, momento em que os interessados podem consignar divergências acerca do projeto e sugerir a imposição de condicionantes a serem observadas na etapa de construção.

A PEC 65/2012 parece ignorar a importância do exercício da democracia direta, quando propõem a autorização para construção de obra causadora de significativo impacto sem a observância da manifestação direta daqueles indivíduos afetados, suscitando um retrocesso no que atine à operacionalização do princípio da participação popular.

\section{CONCLUSÃO}

Como vimos, o licenciamento ambiental no Brasil é um procedimento complexo, em que o Poder Público exige uma série de estudos técnicos visando induzir os empreendedores públicos e privados a internalizem as externalidades negativas decorrentes de atividades causadoras de degradação ambiental.

A PEC 65/12, visando simplificar esse procedimento, autoriza-se a execução dessas obras a partir da simples apresentação do EIA, documento que acaba por substituir a Licença Ambiental.

Além disso, a PEC 65/12 estabelece que essa licença não poderá ser suspensa ou cancelada, salvo a ocorrência de um fato superveniente, de modo que as reivindicações da comunidade afetada pela degradação ambiental decorrente da obra não poderão configurar fatos supervenientes, ainda que estejam relatas no EIA.

Assim, entendemos que a PEC 65/12, tal como está redigida, viola os princípios do poluidor-pagador e da participação popular, uma vez que suprime a instância de participação direta da população na tomada de decisão ambiental, o que irá impossibilitar, na maioria das vezes, a internalização das externalidades negativas decorrentes da obra ou atividade.

\section{REFERÊNCIAS}

ARAGÃO, A. O princípio do poluidor-pagador: pedra angular da política comunitária do ambiente. São Paulo: Instituto O Direito por um Planeta Verde, 2014. (Série Direito Ambiental para o século XXI, v. 1).

BECHARA, E. Uma contribuição ao aprimoramento do instituto da compensação ambiental previsto na lei 9.985/2000. Tese (Doutorado em 
Direito) - Pontifícia Universidade Católica de São Paulo, São Paulo, 2007. Disponível em: http://www.dominiopublico.gov.br/download/teste/arqs/ cp041032.pdf. Acesso em: 25 nov. 2019.

BRASIL. Lei $n$. 6.938, de 31 de agosto de 1981. Dispõe sobre a Política Nacional do Meio Ambiente, seus fins e mecanismos de formulação e aplicação, e dá outras providências. Diário Oficial da República Federativa do Brasil. Brasília, 1981.

BRASIL. Constituição (1988). Constituição da República Federativa do Brasil. Brasília, DF: Senado Federal: Centro Gráfico, 1988.

BRASIL. Decreto n. 99.274, de 6 de junho de 1990. Regulamenta a Lei n. 6.902, de 27 de abril de 1981, e a Lei n. 6.938, de 31 de agosto de 1981, que dispõem, respectivamente sobre a criação de Estações Ecológicas e Áreas de Proteção Ambiental e sobre a Política Nacional do Meio Ambiente, e dá outras providências. Diário Oficial da República Federativa do Brasil. Brasília, 1990.

CONSELHO DA UNIÃO EUROPEIA. Decisão 2005/370/CE relativa à celebração, em nome da Comunidade Europeia, da Convenção sobre o acesso à informação, participação do público no processo de tomada de decisão e acesso à justiça em matéria de ambiente. Bruxelas, 17 fev. 2015. Disponível em: http://eur-lex.europa.eu/legal-content/PT/ TXT/?uri=celex:32005D0370. Acesso em: 25 nov. 2019.

CONAMA - CONSELHO NACIONAL DO MEIO AMBIENTE. Resolução n. 001, de 23 de janeiro de 1986. Brasília, DF: Diário Oficial da União, 1986.

CONAMA - CONSELHO NACIONAL DO MEIO AMBIENTE. Resolução n. 009, de 03 de dezembro 1987. Brasília, DF: Diário Oficial da União, 1990.

CONAMA - CONSELHO NACIONAL DO MEIO AMBIENTE. Resolução n. 237, de 19 de dezembro 1997. Brasília, DF: Diário Oficial da União, 1997.

DEGENSZAJN, D. R. Alteração dos fatos no curso do processo e os limites de modificação da causa petendi. 2010. Dissertação (Mestrado em Direito Processual) - Faculdade de Direito, Universidade de São Paulo, São Paulo, 2010.

FISCHER, F. Citizens, experts, and the environment: the politics of local knowledge. Durham: Duke University Press, 2000. 
GRANZEIRA, M. L. M. Direito ambiental. 3. ed. São Paulo: Atlas, 2014. GURGACZ, A. M. et al. Proposta de Emenda à Constituição n. 65 de 2012. Texto Inicial. Disponível em: https://www25.senado.leg.br/web/ atividade/materias/-/materia/109736. Acesso em: 25 nov. 2016.

GURGACZ,A. M. Relatório à PEC n. 65, de 2012. Disponível em: https:// www25.senado.leg.br/web/atividade/materias/-/materia/109736. Acesso em: 25 nov. 2019.

HARDIN, G. The tragedy of the commons. Science Magazine, v. 162, n. 3859, p. 1243-1248, 1968. Disponível em: http:/www.sciencemag.org/ content/162/3859/1243.full. Acesso em: 25 nov. 2019.

HOWDEN, D. As externalidades e as mudanças climáticas: a importância da subjetividade na economia. 2013. Disponível em: http://mises.org.br/ Article.aspx?id=1736. Acesso em: 25 nov. 2015.

LEITE, J. R. M. (coord.) Manual de direito ambiental. São Paulo: Saraiva, 2015.

MACHADO, P. A. L. Direito ambiental brasileiro. 23. ed. São Paulo: Malheiros, 2015.

OECD - ORGANISATION FOR ECONOMIC COOPERATION AND DEVELOPMENT. Recommendation of the Council on Guiding Principles concerning International Economic Aspects of Environmental Policies C (72)128. Paris: OECD, 1992. Disponível em: https://legalinstruments. oecd.org/en/instruments/OECD-LEGAL-0102 . Acesso em: 25 nov. 2019. ONU - ORGANIZAÇÃO DAS NAÇÕES UNIDAS. Declaração do Rio sobre Meio Ambiente e Desenvolvimento. 14 de junho de 1992. Disponível em: http://www.meioambiente.pr.gov.br/arquivos/File/agenda21/ Declaracao_Rio_Meio_Ambiente_Desenvolvimento.pdf. Acesso em 25 nov. 2019.

PIMENTA, P. R. L.; GORDILHO, Heron J. S., Fins do princípio do poluidor-pagador. Revista Brasileira de Direito IMED, Passo Fundo, v. 14, p. 361-379, 2018. Disponível em: https://seer.imed.edu.br/index.php/ revistadedireito/article/view/2080/1613. Acesso em: 25 nov. 2019.

ROCHA, J. C. S. Direito Ambiental do trabalho: mudanças de paradigma na tutela jurídica à saúde do trabalhador. 2. ed. São Paulo: Atlas, 2013.

RODRIGUES, R. Relatório à PEC n. 65, de 2012. Disponível em: https:// www25.senado.leg.br/web/atividade/materias/-/materia/109736. Acesso em 25 nov. 2019. 
RODRIGUES, R. Senado Federal, Requerimento $n .358$, de 2016a. Disponível em: http://legis.senado.leg.br/diarios/ BuscaDiario?tipDiario=1\&datDiario=19/05/2016\& paginaDireta $=00389$. Acesso em: 25 nov. 2019.

RODRIGUES, R.; GURGACZ, A. M. Requerimento n. 39, de $2016 b$. Disponível em: https://www25.senado.leg.br/web/atividade/materias/-/ materia/109736. Acesso em: 25 nov. 2019.

SARLET, I. W; FENSTERSEIFER, T. Princípios do direito ambiental. São Paulo: Saraiva, 2014.

SENADO FEDERAL. Parecer $n .469$ de 2016 da CCJC. Disponível em: http://legis.senado.leg.br/diarios/ BuscaDiario?tipDiario $=1 \&$ datDiario $=29 / 04 / 2016 \&$ paginaDireta $=00059$. Acesso em: 25 nov. 2019.

STF - SUPREMO TRIBUNAL FEDERAL. Ação Direita de Inconstitucionalidade n. 815-DF. Requerido: Congresso Nacional. Relator: Min. Moreira Alves. Diário da Justiça, 10 maio 1996. Disponível em: http:// redir.stf.jus.br/paginadorpub/paginador.jsp?docTP=AC\&docID $=266547$. Acesso em: 25 nov. 2019.

VEIGA NETO, F. C. A construção dos mercados de pagamento por serviços ambientais e suas implicações para o desenvolvimento sustentável no Brasil. 2008. Tese (Doutorado) - Programa de Pós-Graduação em Desenvolvimento, Agricultura e Sociedade, Universidade Federal Rural do Rio de Janeiro - Rio de Janeiro, 2008.

Artigo recebido em: 13/06/2019.

Artigo aceito em: 04/09/2019.

\section{Como citar este artigo (ABNT):}

GORDILHO, H. J. S.; SIQUEIRA, R. P. S. Proposta de Emenda à Constituição n. 65 de 2012: réquiem ao licenciamento ambiental. Veredas do Direito, Belo Horizonte, v. 16, n. n. 36, p. 279-299, set/dez. 2019. Disponível em: http:/www.domhelder.edu.br/revista/index.php/veredas/ article/view/1562. Acesso em: dia mês. ano. 